\title{
Resveratrol induces apoptosis of benign prostatic hyperplasia epithelial cell line (BPH-1) through p38 MAPK-FOXO3a pathway
}

\author{
Chao Li ${ }^{1,2}$, Wan-Li Hư ${ }^{* *}$ Meng-Xin Lu and Guan-Fa Xiao ${ }^{1}$
}

\begin{abstract}
Background: Resveratrol is reported to inhibit the growth of prostate, which is characteristic of benign prostatic hyperplasia (BPH) condition. However, the mechanism remains unclear. This study aimed to identify the effects and probable mechanism of resveratrol on $\mathrm{BPH}$.

Methods: We used the BPH epithelial cell line BPH-1 to investigate the effect of resveratrol. Cells were treated with various concentrations of resveratrol, and its effects on cells viability, apoptosis, ROS accumulation, and cell cycle were assessed. Western blot was used to examine activation of p38 MAPK and protein levels of FOXO3a, $\mathrm{BCl} 2, \mathrm{BCl}-$ $\mathrm{XL}$, and caspase3. Cells were also co-treated with the p38 MAPK inhibitor SB203580 or ROS scavenger N-Acetyl-Lcysteine (NAC) to further investigate the mechanism.

Results: Resveratrol treatment inhibited the growth of $\mathrm{BPH}-1$ and increased apoptosis of cells. In addition, levels of phosphorylated p38 MAPK level was elevated and FOXO3a repression was observed. Concomitantly, ROS was accumulated. All of these resveratrol-mediated effects were suppressed by additional treatment with SB203580 or NAC. Resveratrol was also found to induce cell cycle arrest at $S$ phase.

Conclusions: Resveratrol can activate p38 MAPK and repress FOXO3a, thereby causing repression of SOD2, catalase, and increase of ROS accumulation, leading to apoptosis in $\mathrm{BPH}-1$ cells.
\end{abstract}

Keywords: Resveratrol, Benign prostatic hyperplasia, p38 MAPK, FOXO3a, Apoptosis, Reactive oxygen species

\section{Background}

Benign prostatic hyperplasia (BPH) is a pathological condition characterized by nonmalignant enlargement of the prostate gland, and is common in elderly men $[1,2]$. It is reported that $50 \%$ of males show histological characteristics of BPH by the age of 50 years and $80 \%$ by the age of 70 years [1]. BPH patients experience frequent micturition or urgent urination, especially at night $[3,4]$. Such lower urinary tract symptoms (LUTS) seriously impair the physical and psychological health of BPH patients. Despite several studies, the exact mechanisms and

\footnotetext{
* Correspondence: huwanli_urology@163.com

'Department of Urology, Zhongnan Hospital of Wuhan University, No. 169 DongHu Road, WuChang District, Wuhan 430000, Hubei, People's Republic of China

Full list of author information is available at the end of the article
}

pathogenesis of BPH remains unclear; nonetheless, the pathological progression certainly involves tissue proliferation of epithelia and stroma $[5,6]$.

Therapy for BPH consists of medical treatment and surgery. Traditional therapy for BPH involves administration of $5 \alpha$-reductase inhibitors and $\alpha$ blockers, which can shrink the prostate gland or alleviate bladder outlet obstruction (BOO). However, these treatments have many side effects, such as gynecomastia and sexual dysfunction, and is not effective in all patients [7]. Therefore, there is a need for more efficient drugs with less side effects to treat $\mathrm{BPH}$.

MAPK signal transduction pathways have been implicated to play key roles in a number of biological processes, including cell growth, differentiation, apoptosis, inflammation, and responses to environmental stresses

(c) The Author(s). 2019 Open Access This article is distributed under the terms of the Creative Commons Attribution 4.0 International License (http://creativecommons.org/licenses/by/4.0/), which permits unrestricted use, distribution, and reproduction in any medium, provided you give appropriate credit to the original author(s) and the source, provide a link to the Creative Commons license, and indicate if changes were made. The Creative Commons Public Domain Dedication waiver (http://creativecommons.org/publicdomain/zero/1.0/) applies to the data made available in this article, unless otherwise stated. 
[8]. It is reported that MAPK/ERK pathway is essential for the proliferation of human prostate $[9,10]$. Resveratrol is a compound found in significant quantities in red wine, grapes, and peanuts [11]. It has anti-proliferation effect in many cancers [12-16] or non-tumor cells [17]. Studies investigating resveratrol have indicated that it can activate p38 MAPK and induce apoptosis of cells $[18,19]$. Recently, a report indicated that resveratrol could enhance apoptosis in $\mathrm{BPH}$-induced rats through apoptotic protein regulation, although the exact mechanism of this effect is not elucidated. The current study aimed at exploring the effects of resveratrol on $\mathrm{BPH}$ and determining whether MAPK pathway is involved in its effects.

\section{Methods}

\section{Reagents and antibodies}

Resveratrol was purchased from Beyotime Biotechnology (Shanghai, China), while 3-(4,5-dimethylthiazol-2-yl)-2,5-diphenyltetrazolium bromide (MTT), dimethylsulfoxide (DMSO), and dichloro-dihydrofluorescein diacetate (DCFH-DA) were procured from Sigma. Phosphorylated-p38 MAPK inhibitor SB203580 and ROS scavenger N-Acetyl-L-cysteine (NAC) were provided by MCE. The primary antibodies for p38 MAPK, phosphorylated-p38 MAPK, and Bcl-xl were obtained from Cell Signaling Technology. Antibodies recognizing Foxo3a, Caspase 3, Bcl2, Catalase, and SOD2 were purchased from Proteintech (China), while anti- $\beta$ actin antibody was purchased from Santa Cruz. The secondary rabbit and mouse-specific antibodies were obtained from Sungene Biotech (China).

\section{Cell culture and treatment}

Benign prostatic hyperplasia epithelial cell line (BPH-1) was obtained from ATCC and cultured in RPMI 1640 medium, supplemented with $10 \%$ fetal bovine serum, and placed in warm and moist environment with 5\% $\mathrm{CO}_{2}$. BPH-1 cells were passaged every 2 days. For treatment, cells were seeded at a density of $30 \times 10^{4}$ per well in 6-well plates, until they reached $80 \%$ confluence. They were incubated with various concentrations of resveratrol, resveratrol plus SB203580, or resveratrol plus NAC.

\section{MTT assay}

BPH-1 cells were seeded in 96 -well plates $\left(5 \times 10^{3}\right.$ cells per well) and incubated at $37{ }^{\circ} \mathrm{C}$ in an incubator containing $5 \% \mathrm{CO}_{2}$. After adherence, cells were treated with diverse concentrations $(0,10,20,30,40$, and $50 \mu \mathrm{M})$ of resveratrol and cultured for 2 days. The cell viability was tested each day. Briefly, after administration, the medium was carefully removed and the cells were incubated in $200 \mu \mathrm{L}$ RPMI 1640 medium containing $0.5 \mathrm{mg} /$
$\mathrm{mL}$ MTT at $37^{\circ} \mathrm{C}$ for $4 \mathrm{~h}$. Then, the supernatant was discarded, $150 \mu \mathrm{L}$ DMSO was added to each well, followed by incubation at room temperature for $10 \mathrm{~min}$. Then, light absorbance was measured at $490 \mathrm{~nm}$.

\section{Apoptosis assessed by flow cytometry}

After administration of the indicated drugs, the apoptosis rate was determined by measuring annexin V-FITC and propidium iodide (PI) (Sungene Biotech Annexin VFITC apoptosis analysis kit, China) via flow cytometry, according to the manufacturer's instructions.

\section{Measurement of ROS production}

Cells were treated with indicated drugs for $24 \mathrm{~h}$ for ROS production measurement, and then harvested, washed with PBS, and incubated with DCFH-DA $(10 \mu \mathrm{M})$ diluted in 1640 medium without FBS. After incubation for $30 \mathrm{~min}$ at $37^{\circ} \mathrm{C}$, the cells were centrifuged and washed with PBS three times to wash away the extracellular DCFH-DA. Then, the cells were submitted to flow cytometry for ROS analysis.

\section{Cell cycle analysis}

For cell cycle analysis, cells were administered the indicated drugs for $24 \mathrm{~h}$, after which they were harvested, centrifuged, washed with PBS, and re-suspended with $1 \times$ DNA staining solution containing PI and permeabilization solution (Multi Science cell cycle staining kit, China). After incubation in dark for $30 \mathrm{~min}$, the cells were analyzed by flow cytometry.

\section{Protein extraction and western blot analysis}

RIPA buffer containing protease inhibitor and phosphatase inhibitor were used to lyse the cells for $30 \mathrm{~min}$ on ice. Afterwards, cells were centrifuged at $12000 \mathrm{~g}$ for 15 min to collect the supernatant. Part of the sample was used to measure the protein concentration by BCA assay (Beyotime Biotechnology BCA Protein Assay Kit, China). The remaining sample was boiled at $100^{\circ} \mathrm{C}$ with $5 \times$ loading buffer for $10 \mathrm{~min}$ and used for western blot analysis, which was performed as described previously [20]. The $\beta$-actin was used as a loading control.

\section{Statistical analyses}

Each experiment was performed more than three times and data are presented as mean \pm standard deviation (SD). One-way ANOVA and student's $t$-test were used to analyze the data. A $P$ value $<0.05$ was considered to be statistically significant. 


\section{Results}

Resveratrol inhibited the growth and promoted apoptosis of $\mathrm{BPH}-1$

To investigate the effect of resveratrol on $\mathrm{BPH}$, we used the $\mathrm{BPH}-1$ cell line as our model. The $\mathrm{BPH}-1$ cells were treated with various concentrations of resveratrol for two days, after which the cell viability was markedly reduced in a time and dose-dependent manner (Fig. 1e). Treatment with $20 \mu \mathrm{M}$ resveratrol for $24 \mathrm{~h}$ inhibited almost half of the cells, while more than $90 \%$ cells were inhibited after administration of $\geq 30 \mu \mathrm{M}$ resveratrol. Furthermore, BPH-1 treatment also induced cell morphological changes; the cell shape was transformed from polygon to spindle, and numerous fragments of cells were observed to be floating on the medium.

To further clarify the growth-inhibitory effect of resveratrol, we investigated apoptosis of BPH-1 using flow cytometry. After treatment with resveratrol for $24 \mathrm{~h}$, the apoptosis rate was significantly enhanced $(P<0.01)$, and increased in a concentration dependent manner (Fig. 1a and $b)$. Together, these data indicated that resveratrol exerts significant cytotoxic effect upon $\mathrm{BPH}-1$ in a dose and time-dependent manner.

ROS accumulation and cell cycle arrest were observed in resveratrol treated $\mathrm{BPH}-1$ cells

Since apoptosis can be regulated through oxidative stress or cell cycle, we evaluated each of these after administration of resveratrol. Compared with vehicle-treated control, the ROS level was notably elevated by 1.8 fold $(P<$ $0.05)$ and 3 fold $(P<0.01)$ after incubation with $20 \mu \mathrm{M}$ and $30 \mu \mathrm{M}$ resveratrol, respectively (Fig. 1c and d). Analysis of cell cycle showed a decreased percentage of cells in G1 phase and high percentage of cells in the $S$ phase after resveratrol treatment (Fig. If and g). These results indicated that ROS accumulation and cell cycle arrest might be involved in the effect of resveratrol.

p38 MAPK activation and FOXO3a down-regulation were involved in the apoptosis of $\mathrm{BPH}-1$

The p38 MAPK pathway is thought to be activated in response to various environmental and cellular stresses,

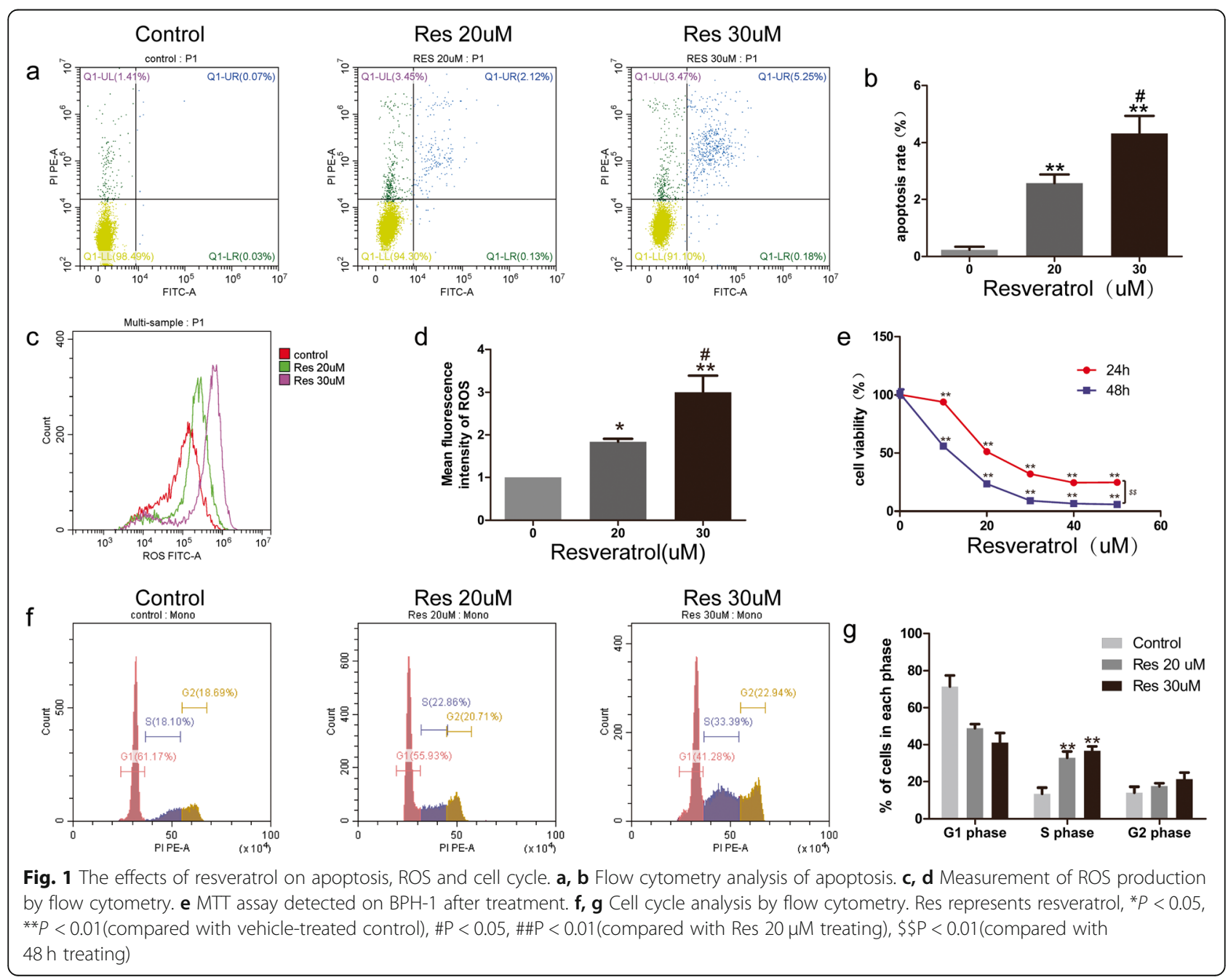


inflammation, and other signals [21]. Since our results suggested increased ROS accumulation by resveratrol treatment, we examined whether this involved the p38 MAPK pathway. Western blot analysis indicated that phosphorylated-p38 MAPK level was significantly increased after resveratrol treatment, although the total p38 MAPK level remained unchanged (Fig. $2 a$ and b). In addition, the level of phosphorylated-p38 MAPK increased with increasing concentrations of resveratrol. Furthermore, the treatment down-regulated FOXO3a protein expression (Fig. 2a). Interestingly, the treatment also down-regulated the expression of anti-apoptotic factors $\mathrm{Bcl} 2$ and $\mathrm{Bcl}-\mathrm{XL}$, while cleaved caspase 3 level was significantly enhanced (Fig. 2a and c). These results suggested that resveratrol may induce apoptosis via p38 MAPK activation and FOXO3a repression.

\section{p38 MAPK inhibitor SB203580 and NAC can alleviate} resveratrol-induced apoptosis and ROS accumulation Next, cells were treated with the p38 MAPK inhibitor SB203580 to investigate whether inhibition of p38 MAPK pathway could reduce apoptosis of $\mathrm{BPH}-1$. The cell viability was significantly increased upon administration of resveratrol plus SB203580 $(p<0.01)$ (Fig. 3e). Moreover, resveratrol-induced apoptosis and ROS accumulation were also ameliorated upon additional treatment of SB203580 (Fig. 3a-d). Treatment with the ROS scavenger NAC elicited similar effects (Fig. 3a-e). Together, these data revealed that the apoptotic effect of resveratrol was mediated via the p38 MAPK pathway and ROS participated in the activation of $\mathrm{p} 38$ MAPK.
Changes in protein level after treatment of $\mathrm{BPH}-1$ with SB203580 and NAC

Protein analysis indicated that treatment with SB203580 and NAC significantly repressed the phosphorylation of p38 MAPK (Fig. 4a and b), and relieved the suppression of FOXO3a protein expression (Fig. 4a). Compared with the resveratrol treatment alone, co-incubation with SB203580 or NAC improved the expression of SOD2 and catalase. Furthermore, $\mathrm{Bcl} 2$ and $\mathrm{Bcl}-\mathrm{XL}$ protein levels were elevated (Fig. 4a), while level of cleaved caspase3 was decreased (Fig. 4a and c) upon the additional treatments. These results indicated that resveratrol may activate p38 MAPK and repress the expression of FOXO3a, causing less ROS clearance and subsequent triggering of apoptosis.

\section{Discussion}

The most important characteristic of $\mathrm{BPH}$ is increased cell proliferation and reduced apoptosis [22]. Therefore, a therapeutic strategy that can enhance apoptosis or cell death in BPH tissue is desirable. Previous study suggested that resveratrol decreases prostate weight in $\mathrm{BPH}$ rats by regulating the expression levels of apoptosis proteins [23]; however, the exact mechanism was not elucidated. In the current study, we demonstrated that resveratrol induces apoptosis via p38 MAPK activation, ROS accumulation, and FOXO3a repression.

MAPKs are involved in four major pathways: the extracellular-signal regulated kinase (ERK), c-jun $\mathrm{N}$ terminal kinase (JNK), Big MAP kinase (BMK), and p38 MAPK [24]. Among these, the p38 MAPK is activated in
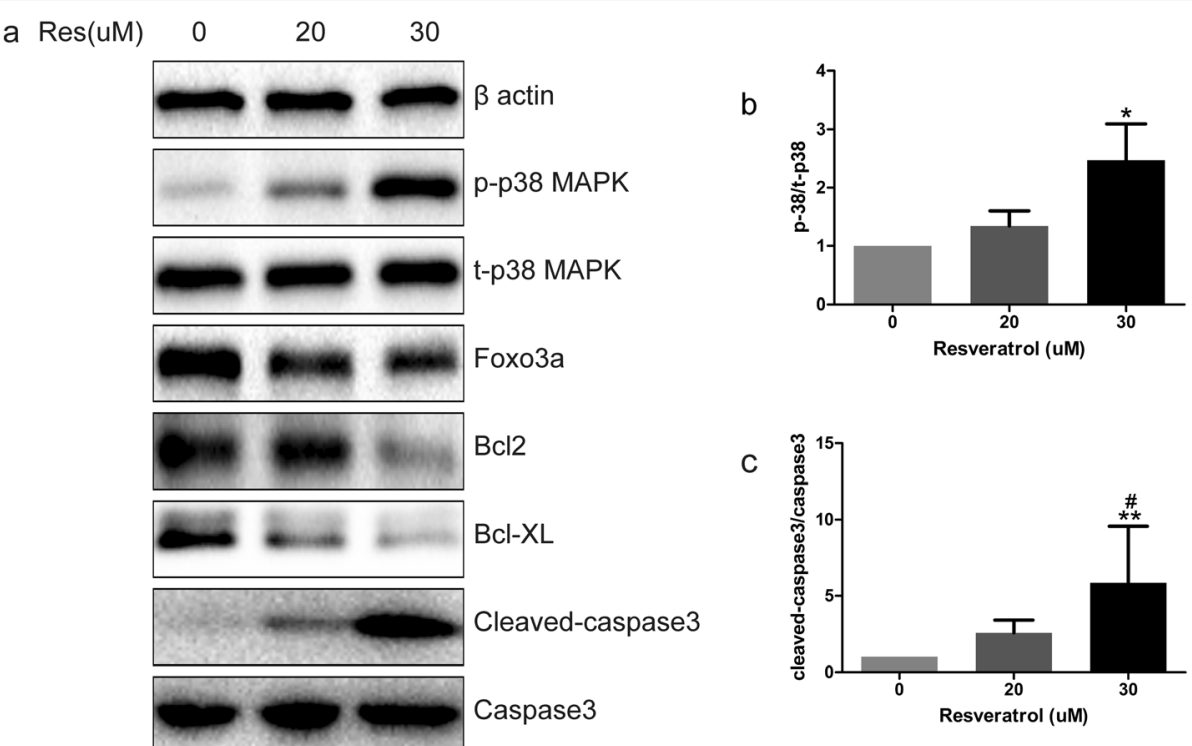

c

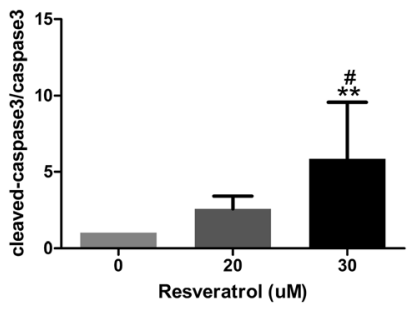

Fig. 2 Western blot analysis after administration. a Western blot stripes of Bactin, p-p38MAPK, p38MAPK, Foxo3a, Bcl2, Bcl-XL, Cleaved-caspase3, Caspase3. b, c One way anova analysis was used to analysis the p-38 and cleaved-caspase3 protein expression, ${ }^{*} P<0.05$ (compared with vehicletreated control), \#P<0.05(compared with Res $20 \mu \mathrm{M}$ treating) 


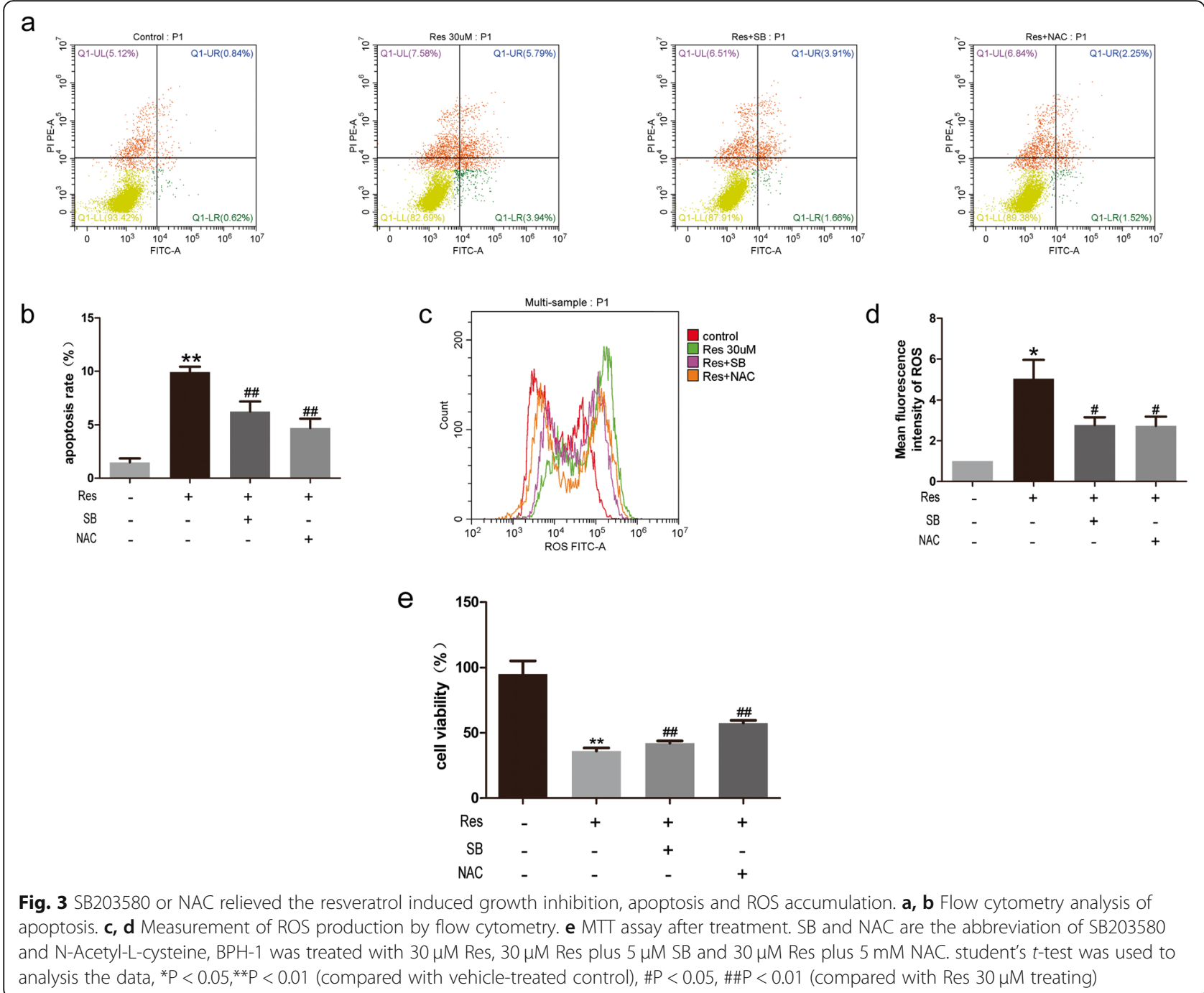

response to cellular stress such as oxidative stress, UV, DNA damage, and inflammatory cytokines [25]. In our study, resveratrol treatment resulted in enhanced activation of p38 MAPK. Notably, treatment with p38 MAPK inhibitor significantly reduced resveratrol-induced phosphorylation of p38 MAPK, ROS accumulation and apoptosis rate. Additionally, treatment with NAC, a ROS scavenger, also produced similar effects. These observations indicated that the apoptotic effect of resveratrol might be exerted via p38 MAPK activation and ROS accumulation. Furthermore, there seems to be a link between p38 MAPK activation and ROS, since NAC treatment could reduce phosphorylation of p38 MAPK.

Studies have reported that FOXO3a, a transcriptional regulator, can trigger apoptosis via up-regulation of proapoptotic and down-regulation of anti-apoptotic genes $[26,27]$. SOD2 and catalase are also vital anti-oxidant enzymes and transcriptional targets of FOXO3a [28]. Our study showed a decreased expression of FOXO3a protein, and concomitant low expression of SOD2 and catalase upon resveratrol treatment. However, this effect could be suppressed by additional treatments with SB203580 or NAC. This indicated that resveratrolmediated p38 MAPK activation might repress the expression of FOXO3a, and thereby reduce levels of SOD2 and catalase, enhance pro-apoptosis gene expression, and repress anti-apoptosis genes expression, leading to apoptosis in BPH-1 cells.

However, our study revealed that mRNA expression of FOXO3a (data not shown) was not altered after resveratrol treatment, contrary to its protein expression. This suggested that post-translational modifications might be involved in FOXO3a repression. In addition, our observations revealed that resveratrol induces cell cycle arrest at $\mathrm{S}$ phase, although the exact mechanism is still not clarified. We aslo observed the different results from those which indicate that resveratrol is a free radical scavenger and an antioxidant $[29,30]$, in our view, the 


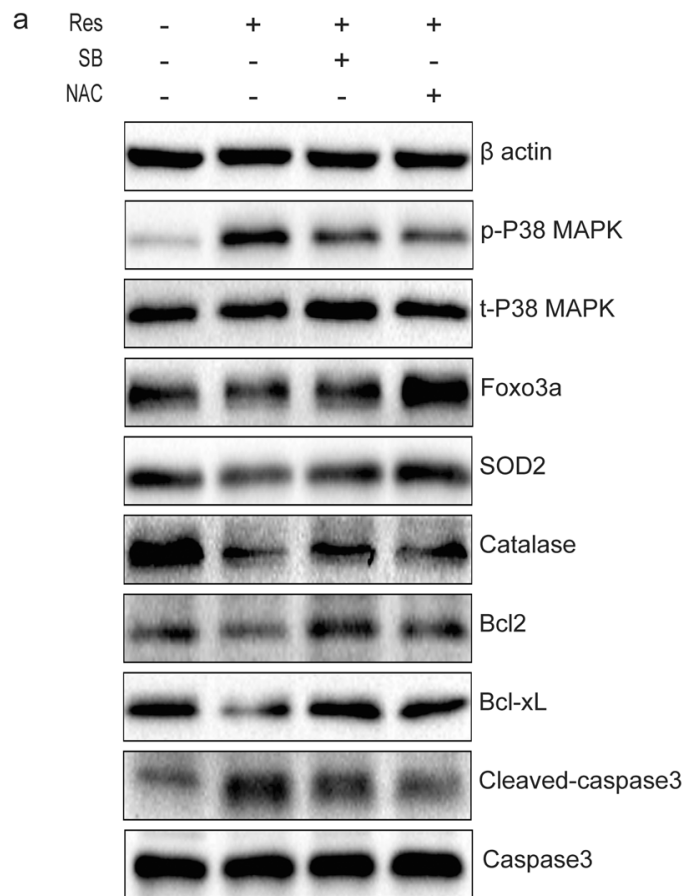

b
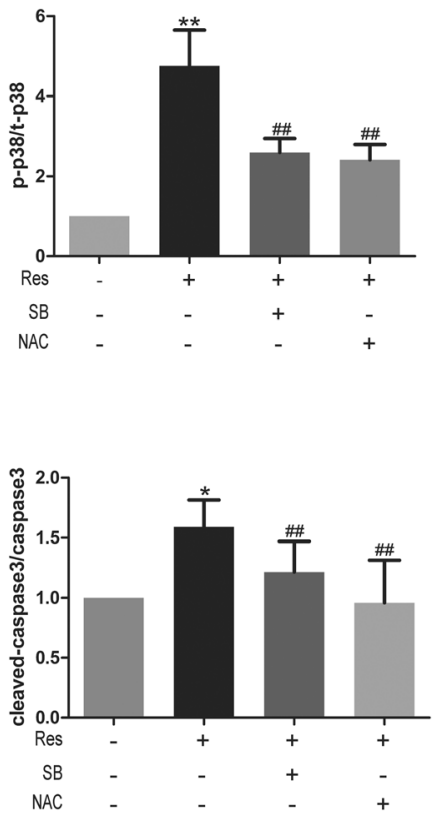

Fig. 4 Western blot analysis after co-incubating with SB203580 or NAC. a Western blot stripes of $\beta$ actin, p-p38MAPK, p38MAPK, SOD2, Catalase, Foxo3a, BCl2, BCl-XL, Cleaved-caspase3, Caspase3. b, c Relative expression of $\mathrm{p}$-38 or cleaved-caspase3 were analysed by student's $t$-test. ${ }^{*} \mathrm{P}<$ $0.05,{ }^{*} \mathrm{P}<0.01$ (compared with vehicle-treated control), \#\#P $<0.01$ (compared with Res $30 \mu \mathrm{M}$ treating)

distinct observation may be due to the cell types, concentrations, time and the diverse conditions before treating with resveratrol (high glucose, hydrogen peroxide) [31]. To the best of our knowledge, this is the first study to reval potential mechanism of the apoptosis effect of resveratrol on $\mathrm{BPH}-1$. It has already been reported that resveratrol can regulate androgen receptors or estrogen receptors in distinct ways [13, 32-34]. These observations, combined with our findings make resveratrol a potential therapeutic agent to treat $\mathrm{BPH}$.

\section{Conclusions}

In conclusion, our study shows that resveratrol can induce apoptosis and ROS accumulation in prostatic hyperplasia epithelial cell line BPH-1 via p38 MAPK regulated FOXO3a repression.

\section{Acknowledgements}

We sincerely appreciate the help provided by ZHANG PENG, CHEN SONG (Department of Urology, Zhongnan Hospital, Wuhan University, Wuhan, Hubei 430071, P. R. China) and SHAN DAN NI, ZHANG SHAN SHAN (Department of medical research center, Zhongnan Hospital, Wuhan University, Wuhan, Hubei 430071, P. R. China) during our study.

\section{Authors' contributions}

LiChao performed most of the experiments of this study and contributed in writing the manuscript. LiChao and Wan-Li Hu designed this study, Wan-Li Hu provided the funding support and gave us guidance, Meng-Xin Lu participated in part of the experiments and gave us technical guidance to the experiments, Guan-Fa Xiao participated in part of the experiments. All authors read and approved the final manuscript.

\section{Funding}

Not applicable.

Availability of data and materials

The datasets generated and analyzed during the current study are available through the corresponding author on reasonable request.

Ethics approval and consent to participate

Not applicable.

Consent for publication

Not applicable.

\section{Competing interests}

The authors declare that they have no competing interests.

\section{Author details}

${ }^{1}$ Department of Urology, Zhongnan Hospital of Wuhan University, No. 169 DongHu Road, WuChang District, Wuhan 430000, Hubei, People's Republic of China. ${ }^{2}$ Department of Obstetrics and Gynaecology, Wuhan Fourth Hospital;

Puai Hospital, Tongji Medical College, Huazhong University of Science and Technology, No.473 HanZheng Street, QiaoKou District, Wuhan 430000, Hubei, People's Republic of China.

Received: 29 December 2018 Accepted: 21 August 2019

Published online: 29 August 2019

\section{References}

1. Paolone DR. Benign prostatic hyperplasia. Clin Geriatr Med. 2010;26(2):22339. https://doi.org/10.1016/j.cger.2010.02.010.

2. Brandon VA, Jack B, Elterman DS. Medical therapy for benign prostatic hyperplasia: a review. Canadian Journal of Urology. 2015;22(5 Suppl 1):7. 
3. Roehrborn CG. Male lower urinary tract symptoms (LUTS) and benign prostatic hyperplasia (BPH). Med Clin N Am. 2011;95(1):87-100. https://doi. org/10.1016/j.mcna.2010.08.013.

4. Oh S-J. Unsolved issues in managing benign prostatic hyperplasia. Korean journal of urology. 2013;54(6):349-50. https://doi.org/10.4111/kju.2 013.54.6.349.

5. MCNeal JE. Regional morphology and pathology of the prostate. Am J Clin Pathol. 1968:49(3):347-57.

6. Roehrborn CG. Pathology of benign prostatic hyperplasia. Int J Impot Res. 2008;20:S11-8. https://doi.org/10.1038/ijir.2008.55.

7. Welliver C, Essa A. Sexual side effects of medical and surgical benign prostatic hyperplasia treatments. The Urologic clinics of North America. 2016;43(3):393-404. https://doi.org/10.1016/j.ucl.2016.04.010.

8. Kim TW, Michniewicz M, Bergmann DC, Wang ZY. Brassinosteroid regulates stomatal development by GSK3-mediated inhibition of a MAPK pathway. Nature. 2012;482(7385):419-22. https://doi.org/10.1038/nature10794.

9. Youn DH, Park J, Kim HL, Jung Y, Kang J, Lim S, Song G, Kwak HJ, Um JY Berberine improves benign prostatic hyperplasia via suppression of 5 alpha reductase and extracellular signal-regulated kinase in vivo and in vitro. Front Pharmacol. 2018;9. https://doi.org/10.3389/fphar.2018.00773.

10. Youn DH, Park J, Kim HL, Jung Y, Kang JW, Jeong MY, Sethi G, Ahn KS, Um JY. Chrysophanic acid reduces testosterone-induced benign prostatic hyperplasia in rats by suppressing $5 a-$-reductase and extracellular signalregulated kinase. Oncotarget 2017, 8(6):9500-9512. doi:https://doi.org/10.1 8632/oncotarget.13430

11. Nwachukwu JC, Srinivasan S, Bruno NE, Parent AA, Hughes TS, Pollock JA, Gjyshi O, Cavett V, Nowak J, Garcia-Ordonez RD et al. Resveratrol modulates the inflammatory response via an estrogen receptor-signal integration network. elife 2014, 3:e02057. doi:https://doi.org/10.7554/eLife.02057.

12. Izquierdo-Torres E, Hernandez-Oliveras A, Meneses-Morales I, Rodriguez G, Fuentes-Garcia G, Zarain-Herzberg A. Resveratrol up-regulates ATP2A3 gene expression in breast cancer cell lines through epigenetic mechanisms. Int J Biochem Cell Biol. 2019;113:37-47. https://doi.org/10.1016/j.biocel.2019.05.020.

13. Jang YG, Go RE, Hwang KA, Choi KC. Resveratrol inhibits DHT-induced progression of prostate cancer cell line through interfering with the AR and CXCR4 pathway. J Steroid Biochem Mol Biol. 2019;192:105406. https://doi. org/10.1016/j.jsbmb.2019.105406.

14. Kim TH, Park JH, Woo JS. Resveratrol induces cell death through ROS-dependent downregulation of Notch1/PTEN/Akt signaling in ovarian cancer cells. Mol Med Rep. 2019;19(4):3353-60. https://doi.org/10.3892/mmr.2019.9962.

15. Frazzi R, Guardi M. Cellular and Molecular Targets of Resveratrol on Lymphoma and Leukemia Cells. Molecules, 2017, 22(6):885-

16. Almeida TC, Guerra CCC, De Assis BLG, de Oliveira Aguiar Soares RD, Garcia CCM, Lima AA, da Silva GN. Antiproliferative and toxicogenomic effects of resveratrol in bladder cancer cells with different TP53 status. Environmental and molecular mutagenesis 2019. doi:https://doi.org/10.1002/em.22297

17. Guan Z, Shen L, Liang H, Yu H, Hei B, Meng X, Yang L. Resveratrol inhibits hypoxia-induced proliferation and migration of pulmonary artery vascular smooth muscle cells by inhibiting the phosphoinositide 3-kinase/protein kinase B signaling pathway. Mol Med Rep. 2017;16(2):1653-60. https://doi. org/10.3892/mmr.2017.6814.

18. Heo J-R, Kim S-M, Hwang K-A, Kang J-H, Choi K-C. Resveratrol induced reactive oxygen species and endoplasmic reticulum stress-mediated apoptosis, and cell cycle arrest in the A375SM malignant melanoma cell line. Int J Mol Med. 2018; 42(3):1427-35. https://doi.org/10.3892/ijmm.2018.3732.

19. Wu X, Xiong M, Xu C, Duan L, Dong Y, Luo Y, Niu T, Lu C. Resveratrol induces apoptosis of human chronic myelogenous leukemia cells in vitro through p38 and JNK-regulated H2AX phosphorylation. Acta Pharmacol Sin. 2015;36(3):353-61. https://doi.org/10.1038/aps.2014.132.

20. Hu Q, Wang G, Peng J, Qian G, Jiang W, Xie C, Xiao Y, Wang X. Knockdown of SIRT1 suppresses bladder Cancer cell proliferation and migration and induces cell cycle arrest and antioxidant response through FOXO3amediated pathways. Biomed Res Int. 2017;2017:3781904. https://doi.org/1 $0.1155 / 2017 / 3781904$.

21. Lu HD, Liu ZC, Zhou LY, Zhou J, Feng XR, Wang B. Influence of the TLR4mediated p38MAPK signaling pathway on chronic intermittent hypoxicinduced rat's oxidative stress and inflammatory cytokines in rats. European review for medical and pharmacological sciences 2019, 23(1):352-360. doi: https://doi.org/10.26355/eurrev_201901_16783.

22. Quiles MT, Arbós MA, Fraga A, de Torres IM, Reventós J, Morote J. Antiproliferative and apoptotic effects of the herbal agent Pygeum africanum on cultured prostate stromal cells from patients with benign prostatic hyperplasia (BPH). The Prostate 2010, 70(10):1044-1053. doi:doi: https://doi.org/10.1002/pros.21138

23. Chung KS, Cheon SY, An HJ. Effects of resveratrol on benign prostatic hyperplasia by the regulation of inflammatory and apoptotic proteins. J Nat Prod. 2015;78(4):689-94. https://doi.org/10.1021/np500810c.

24. Koul HK, Pal M, Koul S. Role of p38 MAP kinase signal transduction in solid tumors. Genes \& Cancer. 2013;4(9-10):342-59. https://doi.org/10.1177/19476 01913507951.

25. Raingeaud J, Gupta S, Rogers JS, Dickens M, Han J, Ulevitch RJ, Davis RJ. Pro-inflammatory cytokines and environmental stress cause p38 mitogenactivated protein kinase activation by dual phosphorylation on tyrosine and threonine. J Biol Chem. 1995;270(13):7420-6.

26. Liu W, Wang X, Liu Z, Wang Y, Yin B, Yu P, Duan X, Liao Z, Chen Y, Liu C, et al. SGK1 inhibition induces autophagy-dependent apoptosis via the mTORFoxo3a pathway. Br J Cancer. 2017;117(8):1139-53. https://doi.org/10.1038/ bjc.2017.293.

27. Li L, Chen S, Sun Y, Kong L, Liu G, Guo P. Matrine inhibits the proliferation of pituitary tumor cells by decreasing Foxo3a phosphorylation and promoting Foxo3a nuclear localization. Exp Ther Med. 2019;17(5):3775-80. https://doi.org/10.3892/etm.2019.7365.

28. Chang TC, Hsu MF, Shih CY, Wu KK. 5-methoxytryptophan protects MSCs from stress induced premature senescence by upregulating FoxO3a and mTOR. Sci Rep. 2017;7(1):11133. https://doi.org/10.1038/s41598-017-11077-4.

29. Xie YK, Zhou X, Yuan HT, Qiu J, Xin DQ, Chu XL, Wang DC, Wang Z. Resveratrol reduces brain injury after subarachnoid hemorrhage by inhibiting oxidative stress and endoplasmic reticulum stress. Neural Regen Res. 2019;14(10):1734-42. https://doi.org/10.4103/1673-5374.257529.

30. Tan C, Zhou H, Wang X, Mai K, He G. Resveratrol attenuates oxidative stress and inflammatory response in turbot fed with soybean meal based diet. Fish \& shellfish immunology. 2019;91:130-5. https://doi.org/10.1016/j.fsi.201 9.05.030.

31. Lucas IK, Kolodziej H. Trans-resveratrol induces apoptosis through ROStriggered mitochondria-dependent pathways in A549 human lung adenocarcinoma epithelial cells. Planta Med. 2015;81(12-13):1038-44. https://doi.org/10.1055/s-0035-1546129.

32. De Amicis F, Chimento A, Montalto Fl, Casaburi I, Sirianni R, Pezzi V. Steroid Receptor Signallings as Targets for Resveratrol Actions in Breast and Prostate Cancer. Int J Mol Sci 2019, 20(5). doi:https://doi.org/10.3390/ijms2 0051087.

33. Lundqvist J, Tringali C, Oskarsson A. Resveratrol, piceatannol and analogs inhibit activation of both wild-type and T877A mutant androgen receptor. J Steroid Biochem Mol Biol. 2017;174:161-8. https://doi.org/10.1016/j.jsbmb.2 017.08.016.

34. Jing Y, Hu T, Lin C, Xiong Q, Liu F, Yuan J, Zhao X, Wang R. Resveratrol downregulates PCSK9 expression and attenuates steatosis through estrogen receptor alpha-mediated pathway in L02cells. Eur J Pharmacol. 2019;855: 216-26. https://doi.org/10.1016/j.ejphar.2019.05.019.

\section{Publisher's Note}

Springer Nature remains neutral with regard to jurisdictional claims in published maps and institutional affiliations.

Ready to submit your research? Choose BMC and benefit from:

- fast, convenient online submission

- thorough peer review by experienced researchers in your field

- rapid publication on acceptance

- support for research data, including large and complex data types

- gold Open Access which fosters wider collaboration and increased citations

- maximum visibility for your research: over $100 \mathrm{M}$ website views per year

At $\mathrm{BMC}$, research is always in progress.

Learn more biomedcentral.com/submission 